\title{
MECHANICAL IMPEDANCES DISTRIBUTED AT THE FINGERS AND PALM OF THE HUMAN HAND SUBJECTED TO 3-D VIBRATIONS
}

\author{
Ren G. Dong*, Daniel E. Welcome*, Thomas W. McDowell*, \\ Xueyan S. Xu*, John Z. Wu*, and Subhash Rakheja** \\ *Engineering and Control Technology Branch, Health Effects Laboratory Division, \\ National Institute for Occupational Safety \& Health, Morgantown, WV, USA \\ **CONCAVE Research Center, Dept. of Mechanical Engineering, \\ Concordia University, Montreal, Canada
}

\begin{abstract}
INTRODUCTION
Vibration biodynamic response of the hand-arm system is useful for designing tools and antivibration devices, for understanding the vibration-induced disorders, and for helping to develop the location-specific frequency weightings for assessing the risk of the hand-transmitted vibration exposure. One of the practical approaches to study the response is to measure the mechanical impedance of the system at the driving-point. Although a considerable number of studies on the impedance along the forearm direction ( $\mathrm{z}_{\mathrm{h}}$-axis) have been reported, the studies of the impedances in $\mathrm{x}_{\mathrm{h}^{-}}$and $\mathrm{y}_{\mathrm{h}}$-axes have been very limited, partially because it is difficult to apply a push force orthogonal to the vibration direction on a single axis vibration testing system. Although the recent developments in 3-D vibration test systems have made it possible to measure impedance responses to multi-axis vibration under controlled grip and push actions ${ }^{1,2}$, a single study has reported the 3-D impedance only in the preliminary stage ${ }^{3}$. Furthermore, no study has investigated the impedances distributed at the fingers and the palm of the hand in the $\mathrm{x}_{\mathrm{h}}$-axis and $\mathrm{y}_{\mathrm{h}}$-axis, which are required for further modeling studies. Therefore, the objectives of this study are to measure the 3-D impedances distributed at the fingers and the palm of the hand and to examine their basic characteristics.
\end{abstract}

\section{METHOD}

Six male and six female subjects participated in the impedance measurement. As shown in Fig. 1, the hand and arm postures used in the measurement were within the ranges specified in ISO $10068(1998)^{4}$. Also consistent with this standard, each subject applied $30 \mathrm{~N}$ grip and $50 \mathrm{~N}$ push on a 3-D instrumented handle equipped with two tri-axial forces sensors (Kistler 9017B/9018B) and a tri-axial accelerometer (Endevco 65-100), which was used to

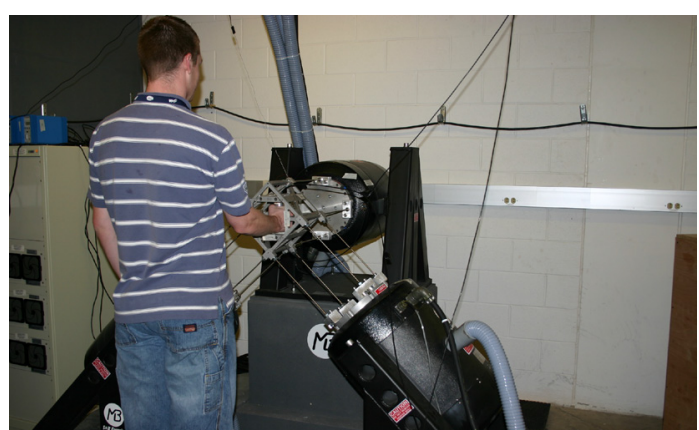

Fig. 1 Test setup and subject posture monitor the grip force and to measure the impedances distributed at the fingers and the palm of the hand in the three orthogonal directions. The push force was measured using a force plate (Kistler 9286AA) on which the subject was standing on during the measurements. In each axis, an identical broad band random vibration spectrum in the 16 to $500 \mathrm{~Hz}$ range was applied as the excitation. To examine the impedance differences between the single and the three-axis excitations, the 1-D impedance for each axis was also measured in a separate test. Three trials were performed for each test treatment, each lasting 30 seconds. 


\section{RESULTS AND DISCUSSION}

Fig. 2 shows the impedances distributed at the fingers and the palm the hand, together with their sum that represents the total impedance of the entire hand-arm system ${ }^{5}$. In all three directions, the impedance distributed at the fingers is much less than that at the palm at frequencies below $100 \mathrm{~Hz}$, which suggests that the effective mass of the fingers at such frequencies is much less than that of the palm. Whereas the magnitudes of the impedance at the fingers in the three directions are fairly comparable, the peak impedance at the palm along the forearm direction is obviously greater than those in the other two directions. The fundamental resonant frequency of the impedance at the palm is lower than that observed from the fingers' responses. The resonant frequency also generally varies with the direction of the vibration exposure but those at the palm are fairly consistent in all three directions (about $40 \mathrm{~Hz}$ ).

\section{REFERENCES}

1. Dong R.G., Welcome D.E., McCormick R., (2006). A novel 3-D hand-arm vibration test system and its preliminary evaluation. Proceedings of the $1^{\text {st }}$ American Conference on Human Vibration, Morgantown, WV, USA.

2. Keller T., Maeda S., Shibata N., (2007). Hand-arm vibration test bench. Proceedings of the $11^{\text {th }}$ International Conference on Hand-Arm Vibration, Bologna, Italy.

3. Rakheja S., Dong R.G., Welcome D.E., and Ahmed A.K.W. (2007). A preliminary study of cross-axis coupling effects in biodynamic response of the hand-arm system. Proceedings of the $11^{\text {th }}$ International Conference on Hand-Arm Vibration, Bologna, Italy.

4. ISO 10068 (1998). Mechanical vibration and shock - Free, mechanical impedance of the human hand-arm system at the driving point. International Organization for Standardization, Geneva, Switzerland.

5. Dong R.G., Welcome D.E., McDowell T.W., Wu J.Z. (2006). Measurement of biodynamic response of human hand-arm system. Journal of Sound and Vibration 294(4-5): 807-827.

DISCLAIMERS: The findings and conclusions in this report are those of the authors and do not necessarily represent the views of the National Institute for Occupational Safety and Health. 